\title{
Characterization and Optical Properties of MnO Doped CuO-Containing Phosphate Glass as Absorption Filters
}

\author{
H.A. Abd El-Ghany \\ Department of Engineering Mathematics and Physics, \\ Faculty of Engineering (Shoubra), Benha University, Cairo, 11629, Egypt. \\ hytham.abdelghany@feng.bu.edu.eg
}

\begin{abstract}
In order to demonstrate the intrinsic and extrinsic changes induced by $\mathrm{MnO}$ in the phosphate glass network, a glass system of composition $44 \mathrm{P}_{2} \mathrm{O}_{5}-38 \mathrm{ZnO}-2 \mathrm{CuO}-(16-x) \mathrm{Na}_{2} \mathrm{O}-x \mathrm{MnO}$ (where, $x=1,2,3,4$, and 5 mol\%) was prepared using the conventional melt quenching technique. XRD patterns confirmed the non-crystalline nature of the prepared samples. The density and molar volume as a function of $\mathrm{MnO}$ content were determined to characterize structure of the obtained glasses. The optical spectroscopic studies of the prepared samples were carried out over (190-1000 nm) spectral range. The prepared samples were found to behave as bandpass filters in the visible region of spectrum. The UV cutoff wavelength was shifted from $308 \mathrm{~nm}$ to $352 \mathrm{~nm}$ by increasing content of $\mathrm{MnO}$ which is very useful in the optical technology requirements such as ultraviolet preventing applications and the protection against UV-LASER. The optical band gap energy was decreased by increasing content of $\mathrm{MnO}$ whilst, the Urbach energy was increased. The decrease in optical band gap was attributed to the progressive increase in non-bridging oxygens (NBOs) concentration with the addition of $\mathrm{MnO}$. The refractive index was found to be enhanced with the addition of $\mathrm{MnO}$ by the effect of increase in overall polarizability. However, the optical polarizability was found to be correlated to the chemical composition of the glass. The results reveal the role of $\mathrm{MnO}$ as a network modifier in the phosphate glass matrix.
\end{abstract}

KEYWORDS: Phosphate glass - Manganese - bandpass filter - Transition metals - Refractive index

\section{INTRODUCTION}

Among different classes of materials, glasses have acknowledged advantages because of their diverse technological and biological applications including solid state lasers, optical fibers, optical filters, water treatment and as biomedical materials [1-3]. Due to the superior physical and optical properties, phosphate glasses have been widely explored by an increasing number of investigations. These glasses have evidence of low melting and softening temperatures as well as strong glass forming character. Phosphate-based glasses are well known to exhibit many other interesting properties such as high thermal expansion coefficients, high electrical conductivity, low thermal conductivity and low dispersion; make these glasses more advantageous than other conventional glass formers such as silicate and borate glasses [4-7]. In addition, the structural versatility of phosphate glasses is of particular interest as it permits the glass network to accommodate a large number of elements so multicomponent glass systems can be easily obtained [8]. However, the highly hygroscopic nature of phosphate glasses is restricted their uses in various technological applications. Hence. many efforts have been made to enhance the chemical stability of phosphate glasses against devitrification and moisture resistant [9].

The majority of the physical and optical properties of phosphate glasses can be greatly changed by the addition of a precisely amount of modifiers including alkali oxides $\left(\mathrm{Na}_{2} \mathrm{O}, \mathrm{Li}_{2} \mathrm{O}, \mathrm{K}_{2} \mathrm{O}\right.$, etc.), alkaline earth oxides $(\mathrm{CaO}, \mathrm{BaO}, \mathrm{MgO}$, etc.) and many other divalent metals ( $\mathrm{ZnO}, \mathrm{CuO}, \mathrm{CdO}, \mathrm{MnO}$ etc.) [10-12]. In view of physical and chemical properties, alkali and alkaline earth oxides have great attention because of several phosphate structural groups created during the reorganization processes. Spectroscopic investigations of $\mathrm{Na}_{2} \mathrm{O}$ doped phosphate glasses indicated that they reveal a strong glass-forming character as well as lower the melting 
point of the composition $[13,14]$. Meanwhile, phosphate glasses with $\mathrm{ZnO}$ have proven to enhance the chemical durability of the glass system since they possess a structure based on $\mathrm{P}-\mathrm{O}-\mathrm{Zn}$ other than P-O-P bonds $[15,16]$.

Phosphate glasses containing transition metal ions such as copper, iron, manganese, cadmium, vanadium, etc., have received increased attention because they generally have interesting optical, electrical and magnetic properties [17-19]. Copper $\left(\mathrm{Cu}^{2+}\right)$ can be acted as a good modifier to enhance the semiconducting properties in phosphate-based glasses [20]. Furthermore, it can modify the absorption behavior of the phosphate-based glass systems and can be considered as a color center in such glass systems [21]. Copper doped phosphate glasses have proven to possess an interesting optical attitude associated with the presence of two optical absorption bands at both the ultraviolet and visible-near infrared regions of spectrum, forming which so called an optical bandpass filter [22]. Optical bandpass filters are well known for their transmission of light only with a certain wavelengths. Apart from these, manganese $\left(\mathrm{Mn}^{2+}\right)$ comes as a network modifier which can exists in different valence states inside the glass matrix. Phosphate-based glasses doped with manganese are interesting due to their structural properties and their coordination [23,24]. It turns out that manganese ions can be utilized as a paramagnetic tool to study the structure and properties of glassy systems, due to the strong influence of manganese ions on optical and magnetic properties of glass [25].

From interesting point of view, copper-containing phosphate glasses doped with a transition metal oxide can be technologically important materials especially when act as optical bandpass filters due to the potential role of the transition metal in controlling the transmission of light. In previous studies [26,27], it is indicated that the parameters of the optical bandpass filers are influenced by the presence of different transition metal ions inside the copper-phosphate glass matrix. The center, height, and width of the transmission band in addition to the filter color were clearly affected by changing the transition metal content. The aim of the present work is to study the role of manganese ions in a copper-phosphate glass matrix as an optical bandpass filters. According to available knowledge, no data has been reported in such subject. Consequently, the physical and optical properties of a proposed glass system with the chemical composition $44 \mathrm{P}_{2} \mathrm{O}_{5}-38 \mathrm{ZnO}-2 \mathrm{CuO}-(16$ $\mathrm{x}) \mathrm{Na}_{2} \mathrm{O}-\mathrm{xMnO}$ (where, $\mathrm{x}=1,2,3,4$, and 5 mol\%) have to be discussed.

\section{EXPERIMENTAL PROCEDURE}

The glasses under study were prepared by the conventional melt quenching technique. Analytically pure grade chemicals of ammonium dihydrogen orthophosphate $\mathrm{NH}_{4} \mathrm{H}_{2} \mathrm{PO}_{4}$, zinc oxide $\mathrm{ZnO}$, sodium carbonate $\mathrm{NaCO}_{3}$, copper oxide $\mathrm{CuO}$ and manganese oxide $\mathrm{MnO}$ were used as starting materials. A glass system with the chemical composition $44 \mathrm{P}_{2} \mathrm{O}_{5}-38 \mathrm{ZnO}-2 \mathrm{CuO}-(16-x) \mathrm{Na}_{2} \mathrm{O}-x \mathrm{MnO}$ (where, $x=1,2,3,4$, and 5 mol\%) was prepared by weighing the required amount of materials, then they were mixed and grinded in a mortar pestle for 30 minutes. The mixture was introduced in a porcelain crucible and heated for one hour in a muffle furnace regulated at $260 \pm 5{ }^{\circ} \mathrm{C}$ to release the gases such as $\mathrm{CO}_{2}$ and $\mathrm{NH}_{3}$. Then the crucible was transferred to the melting furnace at $1000 \pm 5{ }^{\circ} \mathrm{C}$ and was let to melt for one hour. The melt was rotated several times to ensure the maximum homogeneity of the mixture. Finally, the melt was immediately transferred again to the muffle furnace at $260 \pm 5{ }^{\circ} \mathrm{C}$ and casted using stainless steel mould with pressing plate to obtain thin disks of diameters $\approx 2.5 \mathrm{~cm}$. The annealing process is a required step to relive the internal strains and cracks that would remain within glass samples during the quenching process. The molar formula of the glass samples employed in the present work are indicated in Table1.

The density of the prepared glass samples was measured at room temperature using the conventional Archimedes' method, with toluene as an immersion liquid of stable density $\left(0.868 \mathrm{~g} / \mathrm{cm}^{3}\right)$ as [28]:

$\rho=\frac{W_{\text {air }}}{\left(W_{\text {air }}-W_{\text {liq }}\right)} \rho_{o}$

Where, $W_{\text {air }}$ and $W_{\text {liq }}$ are the weights of the sample in air and in liquid respectively. The molar volume was calculated from the molecular weight, $M$ and the density, $\rho$ as [28]: 
$V_{M}=\frac{M}{\rho}$

Table 1. Chemical composition, average molecular weight, density and molar volume of the prepared glass samples.

\begin{tabular}{ccccc}
\hline $\begin{array}{c}\text { Sample } \\
\text { code }\end{array}$ & Chemical composition & $\begin{array}{c}\text { Average molecular } \\
\text { weight, } M \\
(\mathrm{~mol} / \mathrm{g})\end{array}$ & $\begin{array}{c}\text { Density, } \rho \\
\left(\mathrm{g} / \mathrm{cm}^{3}\right)\end{array}$ & $\begin{array}{c}\text { Molar } \\
\text { volume, } V_{M} \\
\left(\mathrm{~cm}^{3} / \mathrm{mole}\right)\end{array}$ \\
\hline PMn1 & $44 \mathrm{P}_{2} \mathrm{O}_{5}-38 \mathrm{ZnO}-2 \mathrm{CuO}-15 \mathrm{Na}_{2} \mathrm{O}-1 \mathrm{MnO}$ & 104.980 & 2.985 & 35.169 \\
$\mathrm{PMn} 2$ & $44 \mathrm{P}_{2} \mathrm{O}_{5}-38 \mathrm{ZnO}-2 \mathrm{CuO}-14 \mathrm{Na}_{2} \mathrm{O}-2 \mathrm{MnO}$ & 105.069 & 3.005 & 34.965 \\
$\mathrm{PMn3}$ & $44 \mathrm{P}_{2} \mathrm{O}_{5}-38 \mathrm{ZnO}-2 \mathrm{CuO}-13 \mathrm{Na}_{2} \mathrm{O}-3 \mathrm{MnO}$ & 105.159 & 3.036 & 34.637 \\
$\mathrm{PMn} 4$ & $44 \mathrm{P}_{2} \mathrm{O}_{5}-38 \mathrm{ZnO}-2 \mathrm{CuO}-12 \mathrm{Na}_{2} \mathrm{O}-4 \mathrm{MnO}$ & 105.249 & 3.069 & 34.294 \\
$\mathrm{PMn} 5$ & $44 \mathrm{P}_{2} \mathrm{O}_{5}-38 \mathrm{ZnO}-2 \mathrm{CuO}-11 \mathrm{Na}_{2} \mathrm{O}-5 \mathrm{MnO}$ & 105.338 & 3.105 & 33.925 \\
\hline
\end{tabular}

\section{RESULTS AND DISCUSSIONS}

\subsection{Characterization and physical studies}

The glass formability of the prepared samples has been examined by means of X-ray diffraction (XRD) technique. The XRD pattern of the prepared glass samples with different $\mathrm{MnO}$ concentrations is indicated in Fig. 1. The diffraction pattern shows a diffuse scattering with no significant crystalline peaks can be observed. This assures the amorphous nature of the prepared samples.

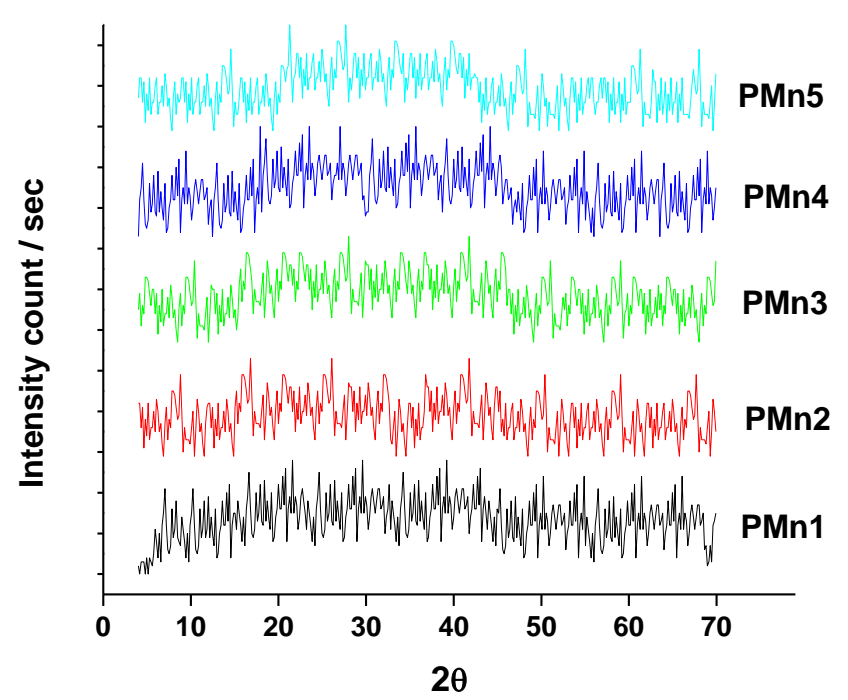

Fig. 1: XRD patterns of the prepared glass samples.

The presence of $\mathrm{MnO}$ with different concentrations in the glass matrix might influence the glass structure due to the potential modification process. The change in glass structure can be demonstrated in terms of the 
molar volume since it depends on the spatial distribution of the ions that compose the glass network. Hence, it is important to determine the glass density from which the molar volume of the glass can be deduced. The variations in the density and the corresponding molar volume of the prepared glass as a function of $\mathrm{MnO}$ concentration are listed in Table 1 and depicted in Fig. 2. It can be noticed that the density is gradually increased from $2.985 \mathrm{gm} / \mathrm{cm}^{3}$ to $3.105 \mathrm{gm} / \mathrm{cm}^{3}$ as the $\mathrm{MnO}$ content is increased. The increase in density can be attributed to the replacement of the low molecular weight $\mathrm{Na}_{2} \mathrm{O}$ by the high molecular weight $\mathrm{MnO}$. On the other hand, the molar volume is found to be linearly decreased from $35.169 \mathrm{~cm}^{-3}$ to $33.925 \mathrm{~cm}^{-3}$ by increasing content of $\mathrm{MnO}$. The decrease in molar volume can be explained by the structural changes in the glass network when $\mathrm{Na}_{2} \mathrm{O}$ is replaced by $\mathrm{MnO}$. This is due to the formation of $\mathrm{P}-\mathrm{O}-\mathrm{Mn}$ bond linkages which construct some new interconnections reticulating the phosphate network and thus lead to close the vitreous structure. It is quite clear that addition of $\mathrm{MnO}$ plays a noticeable role in stabilizing the glass structure. Similar results have been obtained by Omrani et al. 2014 [29].

The concentration of manganese ions and consequently, some other related physical parameters can be determined using the following relations [30]:

Ionic concentration, $N\left(\right.$ ions $\left./ \mathrm{cm}^{-3}\right)=\frac{(\text { Avogadro's No.) }(\text { mole } \% \text { of cation })(\text { glass density) }}{(\text { glass average molecular weight })}$

Mean spacing between manganese ions, $r_{i}\left(A^{o}\right)=(1 / N)^{\frac{1}{3}}$

Polaron radius, $r_{p}\left(A^{o}\right)=\frac{1}{2}(\pi / 6 N)^{\frac{1}{3}}$

Field strength, $F\left(\mathrm{~cm}^{2}\right)=Z / r_{p}^{2}$

Where, $\mathrm{Z}$ is the valence of manganese ions. The calculated values of the ionic concentration, mean $\mathrm{Mn}-\mathrm{Mn}$ spacing, polaron radius and field strength as a function of $\mathrm{MnO}$ content are listed in Table 2 . It can be noticed that both the mean $\mathrm{Mn}-\mathrm{Mn}$ spacing and the polaron radius decrease with increasing content of $\mathrm{MnO}$. This can be related to a decrease in the activation energy with increasing $\mathrm{MnO}$ content [31]. It can be clearly observed that the values of the polaron radius is smaller than that of the mean $\mathrm{Mn}-\mathrm{Mn}$ spacing for all compositions as represented by Fig. 3. Table 2 indicates an increase the ionic concentration with increasing content of $\mathrm{MnO}$ which can be attributed to the decrease in $\mathrm{Mn}-\mathrm{Mn}$ spacing. This seems to be consistent with the obtained results of the density and molar volume. Moreover, the data reveal that a stronger field is generated around the manganese ions with increasing the content of $\mathrm{MnO}$ which seems to be related to the decrease of $\mathrm{Mn}-\mathrm{Mn}$ spacing.

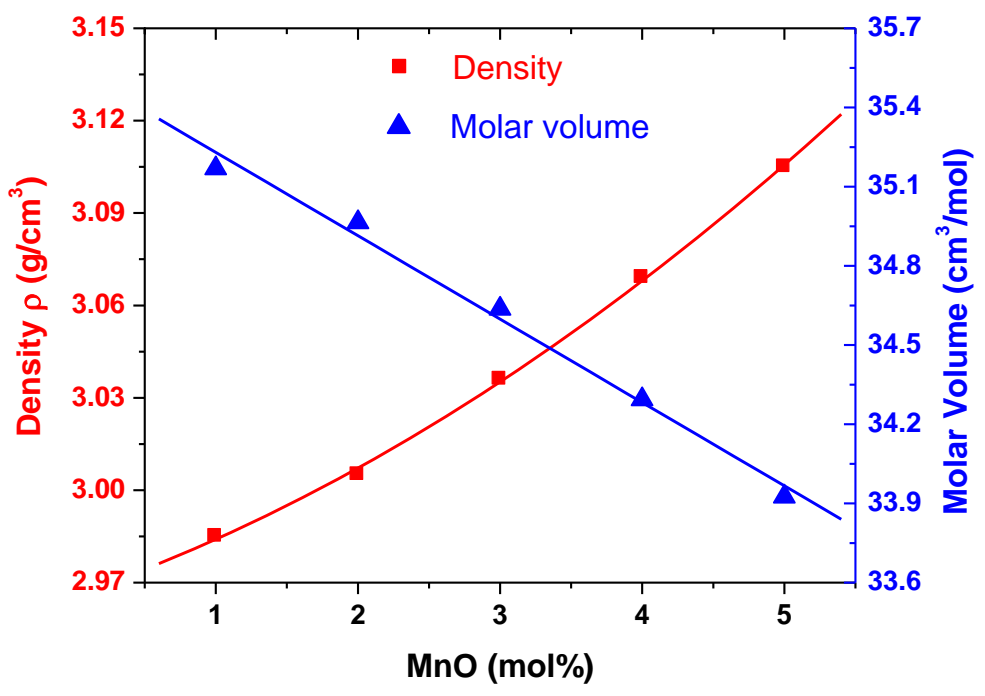

Fig. 2: Variation of density and molar volume with respect to MnO content. 


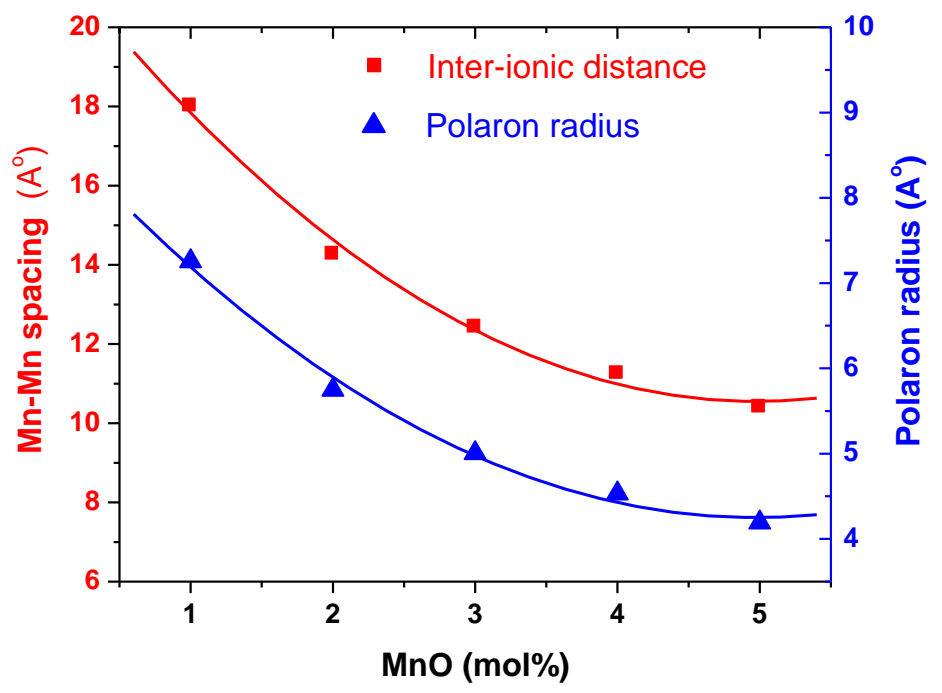

Fig. 3: Variation of manganese ions separation and polaron radius with respect to MnO content.

Table 2. Experimental values of some physical parameters of the prepared glass samples.

\begin{tabular}{lccccc}
\hline Physical parameter & PMn1 & PMn2 & PMn3 & PMn4 & PMn5 \\
\hline Ionic concentration, $N\left(\times 10^{20}\right.$ ions $\left./ \mathrm{cm}^{-3}\right)$ & 1.71 & 3.45 & 5.22 & 7.03 & 8.89 \\
Mean Mn-Mn spacing, $r_{i}\left(A^{\circ}\right)$ & 18.01 & 14.26 & 12.42 & 11.25 & 10.41 \\
Polaron radius, $r_{p}\left(A^{\circ}\right)$ & 7.26 & 5.75 & 5.01 & 4.53 & 4.19 \\
Field strength, $\mathrm{F}\left(\times 10^{14} \mathrm{~cm}^{-2}\right)$ & 3.80 & 6.05 & 7.98 & 9.74 & 11.38 \\
\hline
\end{tabular}

\subsection{Optical investigations}

One of the fundamental tools to characterize the structure of glassy systems is the UV-visible-near IR spectroscopy. The optical spectroscopic analyses of the prepared glass have been carried out over the wavelength range of (190-1000 nm). Figure 4 shows the wavelength dependence of the absorption spectra of the prepared glass samples. A general increase in absorbance with increasing content of $\mathrm{MnO}$ is observed; which can be attributed to the change in the glass composition. The fundamental absorption edge is found to be shifted towards higher wavelength with increasing the content of $\mathrm{MnO}$. The absence of sharp absorption edge supports the non-crystalline nature of prepared glass. Moreover, a broad absorption band in the visiblenear IR can be clearly observed at $800 \mathrm{~nm}$ with no detectable shift can be noticed. This absorption band is assigned to ${ }^{2} \mathrm{~B}_{1 \mathrm{~g}} \rightarrow{ }^{2} \mathrm{~B}_{2 g}$ transition of $\mathrm{Cu}^{2+}$ ions and may be attributed to the superposition of three electron transitions in d-orbitals corresponding to ${ }^{2} \mathrm{~B}_{1 g} \rightarrow{ }^{2} \mathrm{E}_{2},{ }^{2} \mathrm{~B}_{1 g} \rightarrow{ }^{2} \mathrm{~A}_{1 g}$ and ${ }^{2} \mathrm{~B}_{1 g} \rightarrow{ }^{2} \mathrm{~B}_{2 g}$ transitions [32]. Figure 5 shows the wavelength dependence of the transmission spectra of the prepared glass samples. It can be clearly observed that the transmittance is generally decreased with increasing the MnO content which gives the indication of consistency between both of absorption and transmission spectra. In all glass samples, a broad transmission band with sufficiently high intensity can be distinguished in the spectral range 350-800 nm with a meta center at about $520 \mathrm{~nm}$. This means that the prepared glass samples behave as bandpass filters with an appropriate transmission of visible light. 


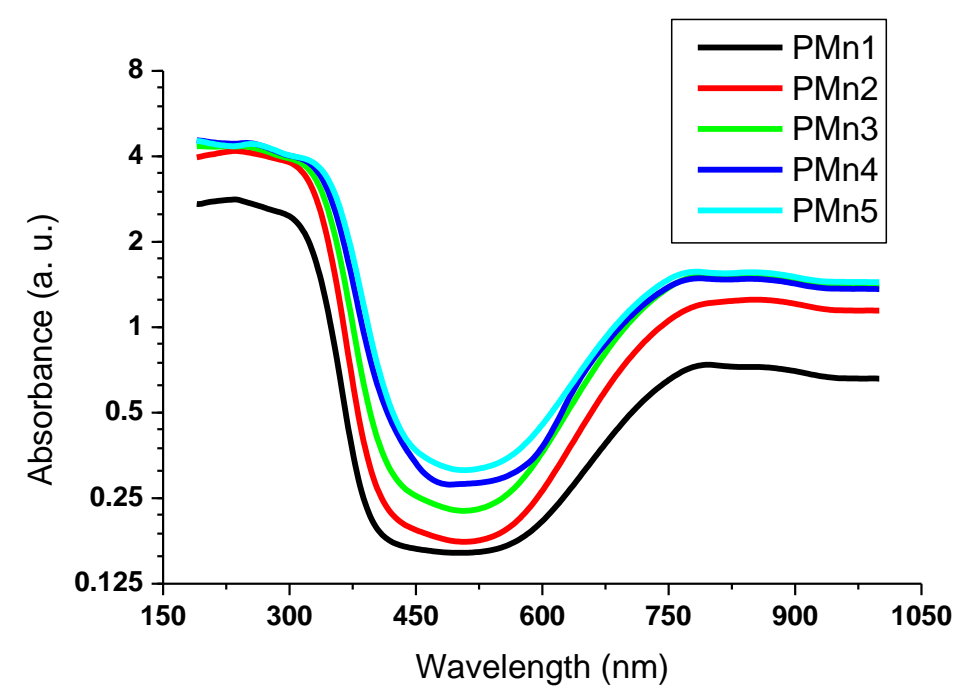

Fig. 4: Absorption spectra of the prepared glass samples.

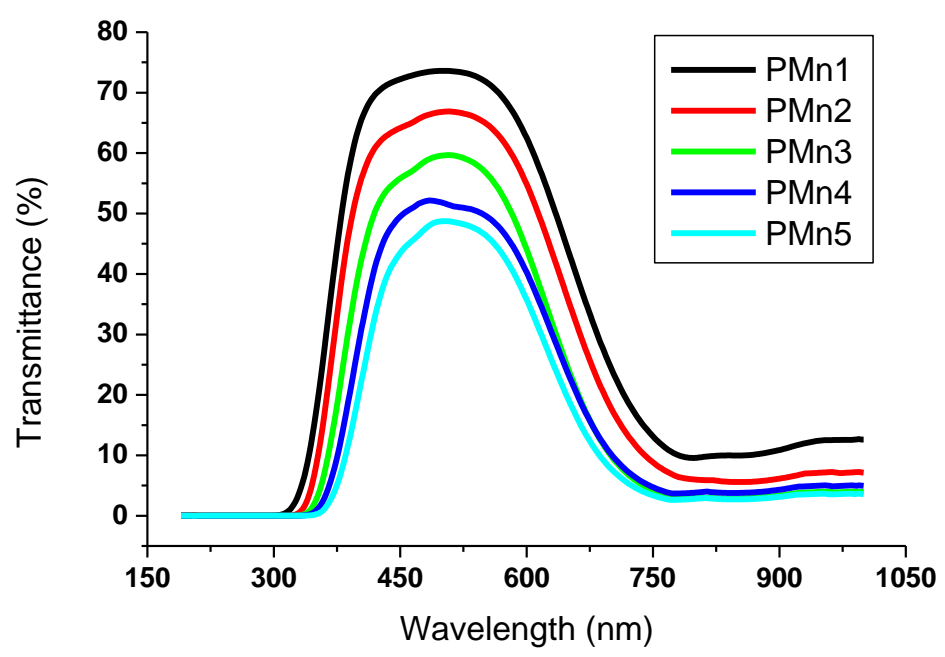

Fig. 5: Transmission spectra of the prepared glass samples.

When dealing with optical bandpass filters, several essential parameters must be taken into account such as peak position, height, width, area, etc. However, one should expect a significant influence of the chemical composition on the transmittance behavior of the obtained bandpass filters due to the potential changes in the characteristics of the transmission band with the addition of $\mathrm{MnO}$. Table 3 represents the transmission band analyses of the obtained bandpass filter glass samples. The intensity of the transmission band is found to be decreased with increasing the $\mathrm{MnO}$ content while slightly changes in the center of the band can be observed. The decrease in the intensity can be related to the increase in density of the glass due to the replacement of $\mathrm{Na}_{2} \mathrm{O}$ by the heavier $\mathrm{MnO}$. The presence of heavy elements in the glass matrix exhibit an increase in the density which might increases the optical absorption and finally decreases the transmission of light $[32,33]$. The UV cutoff wavelength is found to be shifted from $308 \mathrm{~nm}$ to $352 \mathrm{~nm}$ by increasing content of $\mathrm{MnO}$ as depicted in Fig. 6 . The shift of the absorption edge or UV cutoff towards the higher wavelengths can be attributed to the progressive increase in the number of non-bridging oxygens (NBOs) with increasing the content of $\mathrm{MnO}[27,34]$. Such spectral red shift of the UV cutoff is very useful when employing the obtained 
bandpass filters in the optical technology requirements such as ultraviolet preventing applications and the protection from UV-LASER.

Table 3. Experimental values of the optical bandpass filter parameters.

\begin{tabular}{lccccc}
\hline Optical parameter & PMn1 & PMn2 & PMn3 & PMn4 & PMn5 \\
\hline UV band stop (nm) & $190-308$ & $190-324$ & $190-335$ & $190-343$ & $190-352$ \\
Center (nm) & 517 & 516 & 513 & 519 & 521 \\
Width (nm) & 210 & 204 & 185 & 181 & 170 \\
Area (a.u.) & 19877 & 18021 & 14712 & 12360 & 10879 \\
Height (\%) & 74 & 67 & 60 & 53 & 49 \\
\hline
\end{tabular}

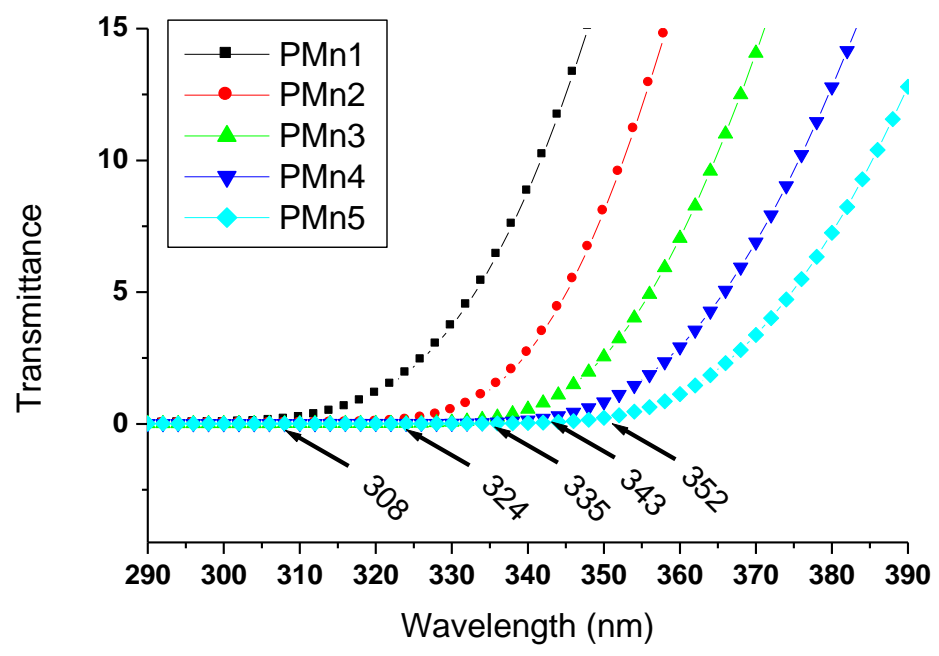

Fig. 6: UV band stop for prepared glass samples.

Once again, the optical absorption measurements can be employed in order to calculate the absorption coefficient as a function of the photon energy using the relation [26-28]:

$\alpha(v)=2.303(A / t)$

Where, $A$ is the absorbance and $t$ is the thickness of the glass sample. Consequently, the optical band gap energy can be evaluated by means of the general relation proposed by Mott and Davies [35]:

$\alpha h v=B\left(h v-E_{g}\right)^{n}$

Where, $B$ is constant and $n$ is an index associated to the mechanism of inter-band electronic transitions. In the above equation $n=1 / 2$ or 2 refers to direct or indirect allowed transitions and $n=3 / 2$ or 3 refers to direct or indirect forbidden transitions. Therefore, the direct and indirect optical band gaps can be evaluated from the plots of $(\alpha h v)^{2}$ and $(\alpha h v)^{1 / 2}$ versus $h v$ as shown in Figs. 7 and 8 respectively. The plots are observed to be linear in the region of strong absorption near the fundamental absorption edge hence, the direct optical band gap 
values can be determined by extrapolating the linear portion of the graph to $(\alpha h v)^{2}=0$ while indirect band gap values can be determined by extrapolating the linear portion of the graph to $(\alpha h v)^{1 / 2}=0$. The experimental values of the direct and indirect optical band gap are listed in Table 4 with an estimated probable error of $\pm 0.02 \mathrm{eV}$.

It is important here to indicate that the structural disorder in the glass network has a notable influence on electronic transitions scheme near the absorption edge. Due to the changes in the chemical composition, there is a chance of producing localized states in the forbidden energy band causing band tails within the band gap. Thus the photons with energy lower than the energy band gap might be absorbed leading to some disorder in the vitreous system [36]. The degree of disorder in the prepared glass samples can be estimated from the width of such band tails described by Urbach energy, $\Delta E$ using the relation [36]:

$\alpha=\alpha_{o} \exp (h v / \Delta E)$

Where, $\alpha$ is the absorption coefficient and $\alpha_{o}$ is constant. As depicted by the representative example in Fig. 9, the logarithmic plots of the absorption coefficient as a function of the photon energy for all glass samples are found to be linear near the absorption edge which verifying the Urbach relation. Therefore, Urbach energy, $\Delta E$ can be easily determined by taking the reciprocal of the slope of the linear region depicted in the Urbach graphs. The experimental values of the Urbach energy are listed in Table 4 with an estimated probable error of $\pm 0.02 \mathrm{eV}$.

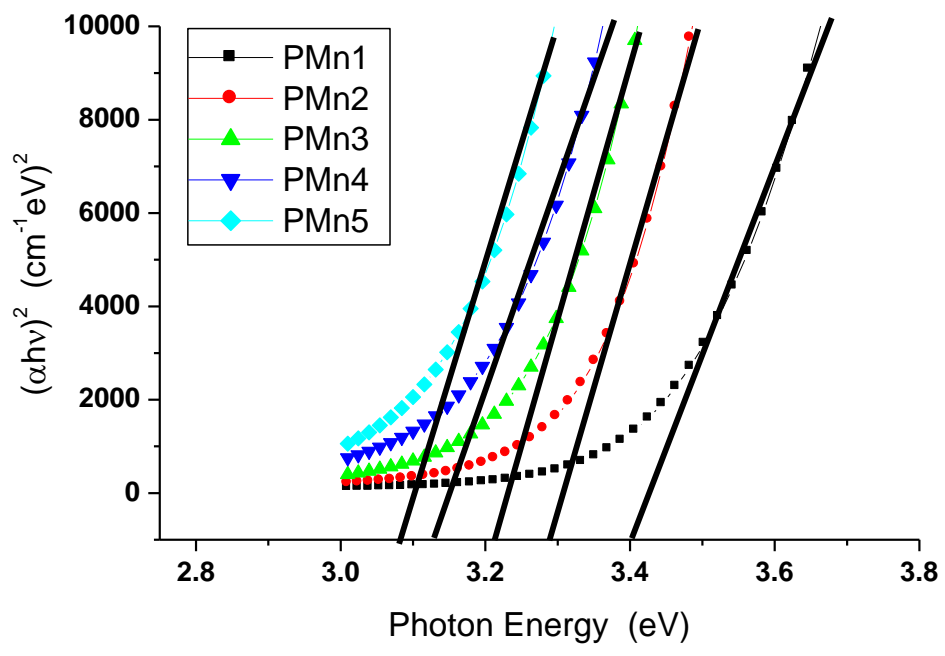

Fig. 7: Determination of the direct optical band gap energy. 


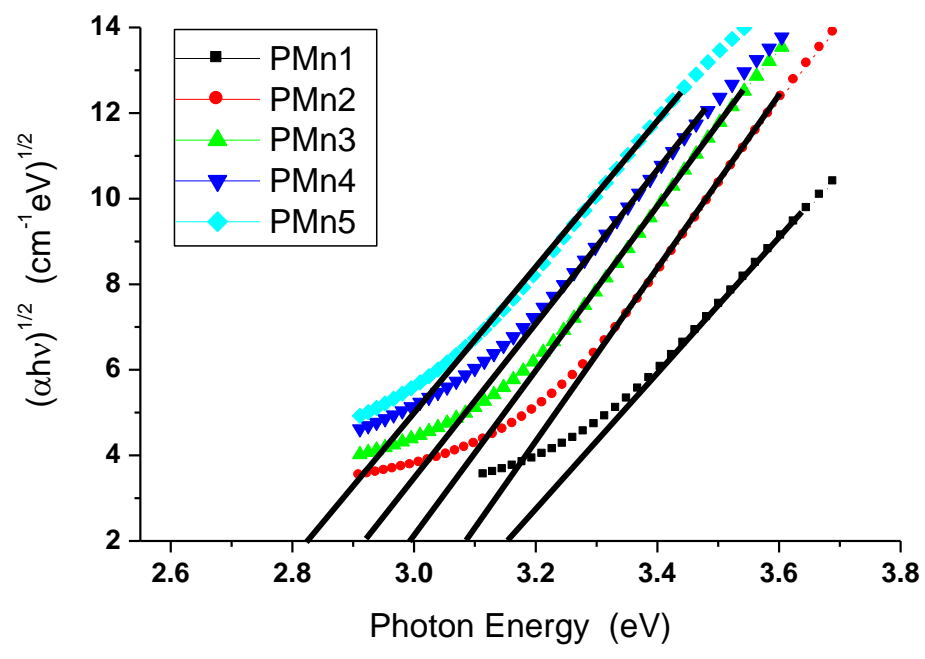

Fig. 8: Determination of the indirect optical band gap energy.

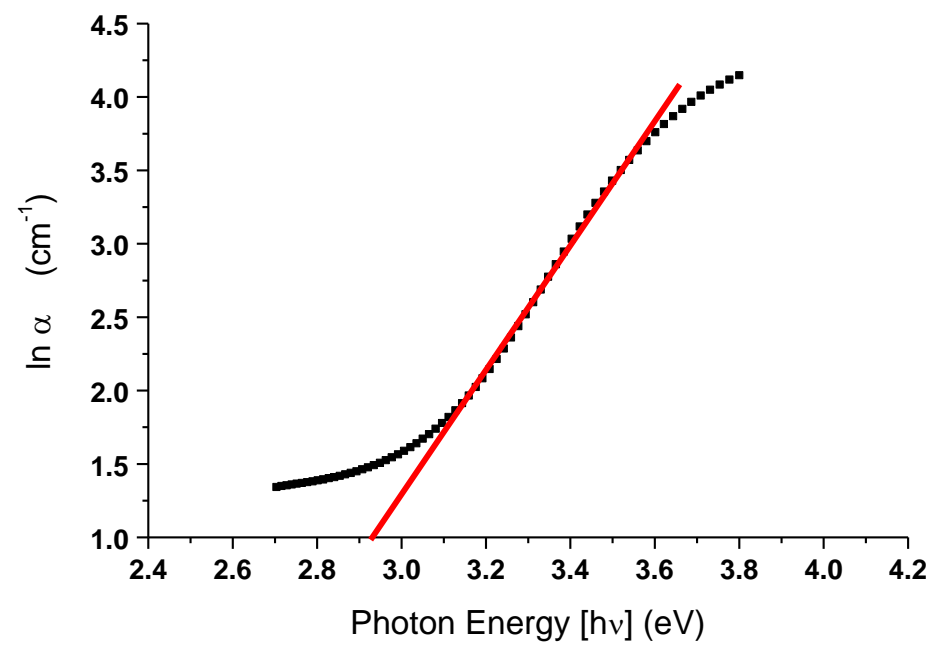

Fig. 9: A representative example for determination of Urbach energy for MnO 2\% content.

Table 4. Direct and indirect optical band gaps, Urbach energy, refractive index and polarizability of the prepared glasses.

\begin{tabular}{lccccc}
\hline Optical parameter & PMn1 & PMn2 & PMn3 & PMn4 & PMn5 \\
\hline Direct optical band gap $(\mathrm{eV})$ & 3.40 & 3.29 & 3.21 & 3.13 & 3.08 \\
Indirect optical band gap $(\mathrm{eV})$ & 3.16 & 3.09 & 2.99 & 2.92 & 2.82 \\
Urabach energy (eV) & 0.222 & 0.235 & 0.252 & 0.284 & 0.303 \\
Refractive index & 2.35 & 2.37 & 2.40 & 2.42 & 2.45 \\
Polarizability $\left(\mathrm{A}^{\circ 3}\right)$ & 0.239 & 0.241 & 0.243 & 2.45 & 2.48 \\
\hline
\end{tabular}


The direct and indirect optical band gaps are found to be linearly decreased with increasing content of $\mathrm{MnO}$ as shown in Fig. 10. The decrease in the optical band gap energy can be attributed to the gradual increase in the concentration of the non-bridging oxygen ions (NBOs) that binds the excited electrons much weakly than the bridging oxygen. The replacement of $\mathrm{Na}_{2} \mathrm{O}$ with $\mathrm{MnO}$ in the glass matrix indicates an increase of the divalent $\mathrm{Mn}^{2+}$ ions (create two non-bridging oxygens in the phosphate network) at the expense of the monovalent $\mathrm{Na}^{+}$ions (create one non-bridging oxygen in the phosphate network) causing a progressive increase in the number of the non-bridging oxygens [34]. It can be observed that the direct optical band gap is ranged from $3.40 \mathrm{eV}$ to $3.08 \mathrm{eV}$ while the indirect optical band gap is ranged from $3.16 \mathrm{eV}$ to $2.82 \mathrm{eV}$. The smaller values of the indirect band gap can be attributed to the presence of the localized energy states in the forbidden band as evaluated by the Urbach energy. As presented in Table 4, the Urbach energy values are found to be increased from $0.222 \mathrm{eV}$ to $0.303 \mathrm{eV}$ which indicate more structural disorder in the glass system with increasing content of $\mathrm{MnO}$ [37].

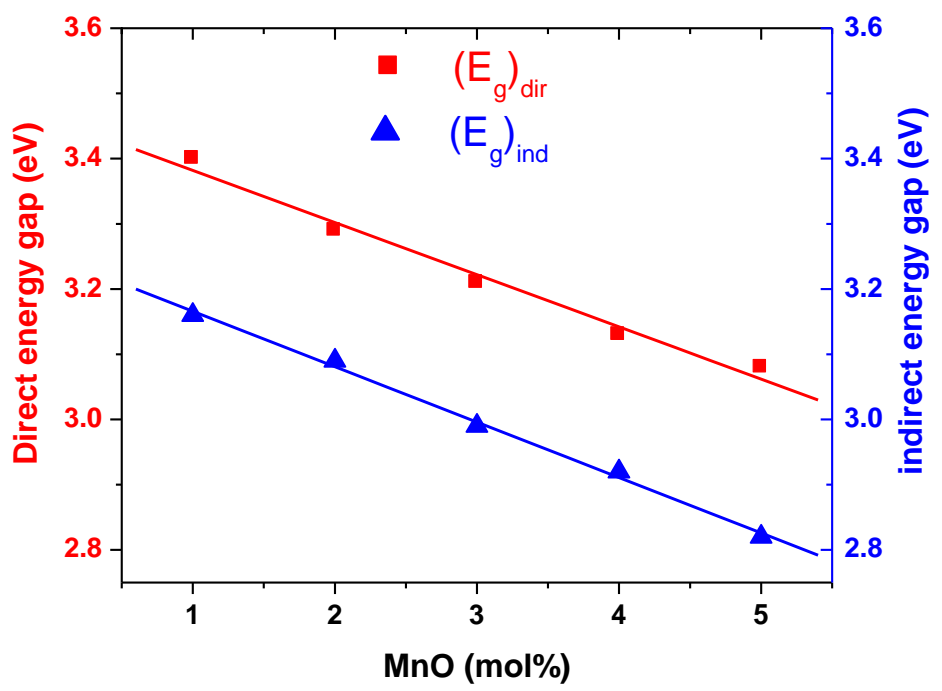

Fig. 10: Variation of direct and indirect optical band gap energy with respect to MnO content.

Determination of the refractive index is of great importance in the glassy materials as it provides significant information about the interaction of light with the vitreous matrix. The refractive index can be determined for different glass samples by means of the Lorenz-Lorenz equation [38,39]:

$\frac{n^{2}-1}{n^{2}+2}=1-\sqrt{\frac{E g}{20}}$

Where, $E_{g}$ is the optical band gap energy. The experimental values of the refractive index for different prepared glass samples are listed in Table 4 and the compositional dependence of the calculated values of the refractive index is depicted in Fig. 11. The data reveal an increase of the refractive index which can be attributed to the changes in glass composition with increasing the $\mathrm{MnO}$ content. This can be understood on the basis that the refractive index is greatly related to the overall polarizability of the glass system. Optical polarizability is a property of optical materials that expresses the response of the electrons when exposing to an external electric field hence, polarizability can be considered as a measure of the degree of deformation of the valence electron cloud in the glassy systems [40]. Generally, the presence of highly polarizable cations to the glass matrix causes effective retardation of the light propagation through the vitreous network leading to a notable increase in the refractive index [41]. Therefore, The addition of a higher polarizable species such as $\mathrm{Mn}^{2+}$ (cation polarizability $=0.554 \mathrm{~A}^{\circ}$ ) at the expense of lower polarizable $\mathrm{Na}^{+}$(cation polarizability $=0.181 \mathrm{~A}^{\circ}$ ) [42] could be the reason for increasing of the refractive index. The polarizability of the prepared glass samples can be deduced through Lorenz-Lorenz equation as [43]: 
$\alpha_{M}=\frac{3}{4 \pi N_{A}} \frac{n^{2}-1}{n^{2}+2}$

Where, $N_{A}$ is the Avogadro's number. The calculated values of the optical polarizability for different prepared glass samples are listed in Table 4. One should expect that the refractive index and the optical polarizability must have the same trend and are depicted in Fig. 11. It is quite clear that the chemical composition of the glass (i.e., replacing of $\mathrm{Na}_{2} \mathrm{O}$ by $\mathrm{MnO}$ ) plays the main role in changing both the refractive index and the optical polarizability.

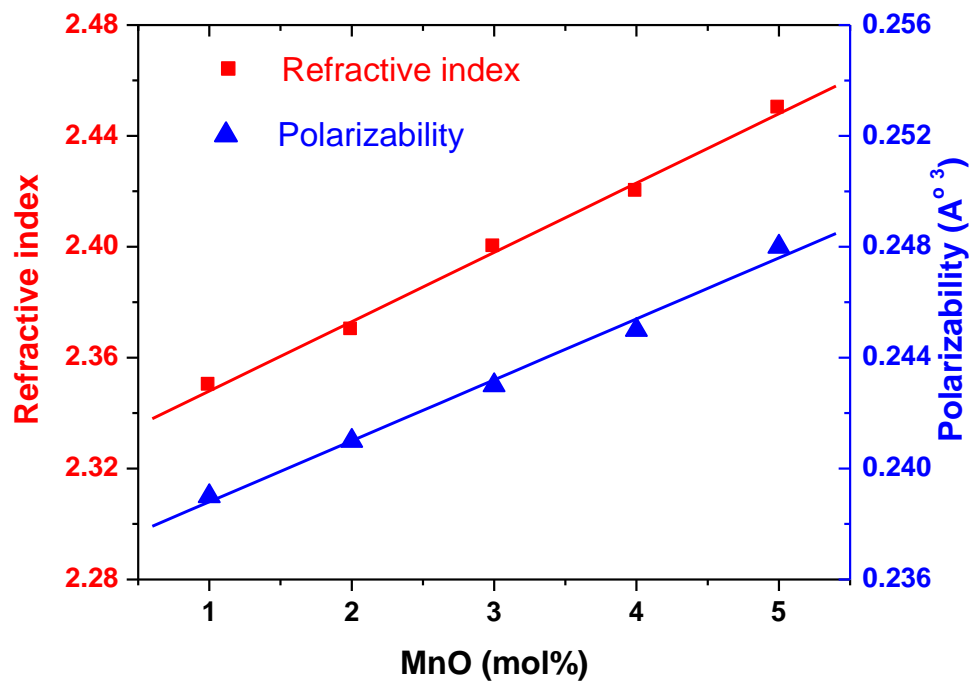

Fig. 11: Compositional dependent of refractive index and polarizability.

\section{CONCLUSIONS}

Glass system of composition $44 \mathrm{P}_{2} \mathrm{O}_{5}-38 \mathrm{ZnO}-2 \mathrm{CuO}-(16-x) \mathrm{Na}_{2} \mathrm{O}-x \mathrm{MnO}$ (where, $x=1,2,3,4$, and 5 mol\%) was prepared using the conventional melt quenching technique. The density was found to be increased with increasing content of $\mathrm{MnO}$ while the molar volume showed an opposite trend by which it was indicated that $\mathrm{MnO}$ played a noticeable role in stabilizing the glass structure. The ionic concentration of manganese ions, mean $\mathrm{Mn}-\mathrm{Mn}$ spacing, polaron radius and field strength were calculated. The optical spectroscopic studies of the prepared samples were carried out over (190-1000 nm) spectral range. The prepared samples were found to behave as bandpass filters in the visible region of spectrum. The optical analyses of the transmission band of the obtained bandpass filters were determined. The direct optical band gap was ranged from $3.40 \mathrm{eV}$ to $3.08 \mathrm{eV}$ while the indirect optical band gap is ranged from $3.16 \mathrm{eV}$ to $2.82 \mathrm{eV}$. The decrease in optical band gap was attributed to the progressive increase in non-bridging oxygens (NBOs) concentration with the addition of $\mathrm{MnO}$. The Urbach energy values is found to be increased from $0.222 \mathrm{eV}$ to $0.303 \mathrm{eV}$ which indicate more structure disorder in the glass system with increasing content of $\mathrm{MnO}$. The compositional dependent of the refractive index and optical polarizability of the obtained glasses were evaluated. The increase of refractive index with increasing content of $\mathrm{MnO}$ is attributed to the increase of the overall polarizability of the glasses due to the addition of a higher polarizable species of $\mathrm{Mn}^{2+}$ at the expense of lower polarizable species of $\mathrm{Na}^{+}$. The results revealed the modifier role of $\mathrm{MnO}$ in the phosphate glass network.

\section{ACKNOWLEDGMENT}

Deep thanks to Dr. Ahmed El-Basaty, Faculty of Industrial Education, Helwan University; for his help and facilitating the use the equipment for preparing the glass samples. 


\section{REFERENCES}

1. N.P. Bansal and R.H. Doremus, "Handbook of Glass Properties", Academic Press, 1986.

2. J.H. Campbell, J.S. Hayden and A. Marker, "High-power solid-state lasers: a laser glass perspective", Int. J. Appl. Glass Sci., vol. 2, pp. 3-29, 2011.

3. J.S. Fernandes, P. Gentile, R.A. Pires, R.L. Reis and P.V. Hatton, "Multifunctional bioactive glass and glass-ceramic biomaterials with antibacterial properties for repair and regeneration of bone tissue", Acta Biomater., vol. 59, pp. 2-11, 2017.

4. R.K. Brow, "Review: the structure of simple phosphate glasses", J. Non-Cryst. Solids, vol. 263-264, pp.1$28,2000$.

5. P. Pascuta, G. Borodi, N. Jumate, I. Vida-Simiti, D. Viorel and E. Culea, "The structural role of manganese ions in some zinc phosphate glasses and glass ceramics" J. Alloy. Compd., vol. 504, pp. 479-483, 2010.

6. B.P. Choudhary and N.B. Singh, "Properties of silver phosphate glass in the presence of nanosize cobalt and nickel oxides", J. Non-Cryst. Solids, vol. 440, pp. 59-69, 2016.

7. H.A. Abd El-Ghany, "Development of a New Glass for Both Visible and Near-Infrared Optical Applications" Key Eng. Mater., vol. 786, pp. 224-235, 2018.

8. B.P. Choudhary, S. Rai and N.B. Singh, "Properties of silver phosphate glass doped with nanosize zinc oxide", Ceram. Int., vol. 42, pp. 10813-10825, 2016.

9. S. Li, Y. Lu, Y. Qu, Y. Xu, L. Ming, Z. Song and Y. Yue, "Influences of ZnO on the chemical durability and thermal stability of calcium iron phosphate glasses", J. Non-Cryst. Solids, vol. 498, pp. 228-235, 2018.

10. G. Murali Krishna, Y. Gandhi, N. Venkatramaiah, R. Venkatesan and N. Veeraiah, "Features of the local structural disorder in $\mathrm{Li}_{2} \mathrm{O}-\mathrm{CaF}_{2}-\mathrm{P}_{2} \mathrm{O}_{5}$ glass-ceramics with $\mathrm{Cr}_{2} \mathrm{O}_{3}$ as nucleating agent", Physica $\mathrm{B}$, vol. 403, pp. 702-710, 2008.

11. M. Altaf and M.A. Chaudhry, "Physical Properties of Lithium Containing Cadmium Phosphate Glasses", J. Mod. Phys., vol. 1, pp. 201-205, 2010.

12. C. Ivascu, I.B. Cozar, L. Daraban and G. Damian, "Spectroscopic investigation of $\mathrm{P}_{2} \mathrm{O}_{5}-\mathrm{CdO}-\mathrm{Li}_{2} \mathrm{O}$ glass system", J. Non-Cryst. Solids, vol. 359, pp. 60-64, 2013.

13. Y.M. Moustofa, K. El-Egili, "Infrared spectra of sodium phosphate glasses", J. Non-Cryst. Solids, vol. 240, pp. 144-153, 1998.

14. 11. M. Altaf, M.A. Chaudhry. "Physical properties of sodium cadmium phosphate glasses" Inter. J. Modern Phys. B, vol. 25, pp. 3503-3512, 2011.

15. R.K. Brow, D.R. Tallant, S.T. Myers and C.C. Phifer, "The short-range structure of zinc polyphosphate glass", J. Non-Cryst. Solids, vol. 191, pp. 45-55, 1995.

16. K. Suzuya, K. Itoh, A. Kajinami and C.K. Loong, "The structure of binary zinc phosphate glasses", J. NonCryst. Solids, vol. 345-346, pp. 80-87, 2004.

17. M. Ahmad, F. Salman, M. Morsi, K. El-Badry and F. Metwall, "Electrical Properties of Some CopperContaining Phosphate Glasses", J. Mater. Sci., vol. 41, pp.1667-1669, 2006. 
18. N.K. Mohan, M.R. Reddy, C.K. Jayasankar and N. Veeraiah, "Spectroscopic and dielectric studies on $\mathrm{MnO}$ doped $\mathrm{PbO}-\mathrm{Nb}_{2} \mathrm{O}_{5}-\mathrm{P}_{2} \mathrm{O}_{5}$ glass system", J. Alloy. Comp., vol. 458, pp. 66-76, 2008.

19. X. $\mathrm{Li}, \mathrm{A}$. Lu and $\mathrm{H}$. Yang, "Structure of $\mathrm{ZnO}-\mathrm{Fe}_{2} \mathrm{O} 3-\mathrm{P}_{2} \mathrm{O}_{5}$ glasses probed by Raman and IR spectroscopy", J. Non-Cryst. Solids, vol. 389, pp. 21-27, 2014.

20. G. Broglia, C. Mugoni, C. Siligardi and M. Montorsi, "Lithium and copper transport properties in phosphate glasses: A Molecular Dynamics study, J. Non-Cryst. Solids, vol. 481, pp. 522-529, 2018.

21. D.A. Magdas, R. Stefan, D. Toloman and N.S. Vedeanu, "Copper ions influence on lead-phosphate glass network", J. Mol. Struct., vol. 1056-1057, pp. 314-318, 2014.

22. H. Elhaes, M. Attallah, Y. Elbashar, M. El-Okr, M. Ibrahim, "Application of $\mathrm{Cu}_{2} \mathrm{O}$-doped phosphate glasses for bandpass filter" Physica B: Cond. Matt., vol. 449, pp. 251-254, 2014.

23. P. Pascuta, M. Bosca, G. Borodi and E. Culea, "Thermal, structural and magnetic properties of some zinc phosphate glasses doped with manganese ions", J. Alloy. Compd., vol. 509, pp. 4314-4319, 2011.

24. W. Ahmina, M. El Moudane, M. Zriouil and M. Taibi, "Glass-forming region, structure and some properties of potassium manganese phosphate glasses", Phase Transit., vol. 89, pp. 1-11, 2016

25. S.S. Sastry and B.R. Rao, "Spectroscopic characterization of manganese-doped alkaline earth lead zinc phosphate glasses", Bull. Mater. Sci., vol. 38, pp. 475-482, 2015.

26. Y.H. Elbashar, H.A. Abd El-Ghany, "Optical spectroscopic analysis of $\mathrm{Fe}_{2} \mathrm{O}_{3}$ doped $\mathrm{CuO}$ containing phosphate glass", Opt. Quant. Electron. 49:310, pp. 1-13, 2017.

27. H. Abd El-Ghany, "Cadmium Doped Copper Containing Phosphate Glass as a Bandpass Filter for Solar Cell Protection", J. Adv. Phys., vol. 14, pp. 5488-5503, 2018.

28. N. Aboulfotoh, Y. Elbashar, M. Ibrahem, M. Elokr, "Characterization of copper doped phosphate glasses for optical applications" Ceram. Int., vol. 40, pp.10395-10399, 2014.

29. R.O. Omrani, S. Krimi, J.J. Videau, I. Khattech, A. El Jazouli and M. Jemal, "Structural investigations and calorimetric dissolution of manganese phosphate glasses", J. Non-Cryst. Solids, vol. 389, pp. 66-71, 2014.

30. A.S. Rao, Y.N. Ahammed, R.R. Reddy, T.V.R. Rao, "Spectroscopic studies of Nd3+-doped alkali fluoroborophosphate glasses", Opt. Mater., vol. 10, pp. 245-252, 1998.

31. M.M. Ahmed, C.A. Hogarth and M.N. Khan, "A study of the electrical and optical properties of the $\mathrm{GeO}_{2}-\mathrm{TeO}_{2}$ glass system", J. Mater. Sci. Lett., vol. 19, pp. 4040-4044, 1984.

32. Ch. Tirupataiah, T. Narendrudu, S. Suresh, P. Srinivasa Rao, P.M. Vinaya Teja, M.V. Sambasiva Rao, G. Chinna Ram and D. Krishna Rao, "Influence of valence state of copper ions on structural and spectroscopic properties of multi-component $\mathrm{PbO}-\mathrm{Al}_{2} \mathrm{O}_{3}-\mathrm{TeO}_{2}-\mathrm{GeO}_{2}-\mathrm{SiO}_{2}$ glass ceramic system- a possible material for memory switching devices", Opt. Mater., vol. 73, pp. 7-15, 2017.

33. Y.H. Elbashar - M.M. Rashad and D. A. Rayan, "Protection Glass Eyewear Against a YAG Laser Based on a Bandpass Absorption Filter", Silicon 9, pp. 111-116, 2017.

34. K. Subrahmanyam, M. Salagram, "Optical band gap studies on (55-x) $\mathrm{Na}_{2} \mathrm{O}-\mathrm{xPbO}-45 \mathrm{P}_{2} \mathrm{O}_{5}$ (SLP) glass system" Opt. Mater., vol. 15, pp. 181-186, 2000. 
35. S.F. Khor, Z.A. Talib, F. Malek and E.M. Cheng, "Optical properties of ultraphosphate glasses containing mixed divalent zinc and magnesium ions" Opt. Mater., vol. 35, pp. 629-633, 2013.

36. A.K. Sandhu, S. Singh and O.P. Pandey, "Neutron irradiation effects on optical and structural properties of silicate glasses" Mater. Chem. Phys., vol. 115, pp. 783-788, 2009.

37. A.H. Khafagy, A.A. El-Adawy, A.A. Higazy, S. El-Rabaie, A.S. Eid, "Studies of some mechanical and optical properties of: $(70 \mathrm{x}) \mathrm{TeO}_{2}+15 \mathrm{~B}_{2} \mathrm{O}_{3}+15 \mathrm{P}_{2} \mathrm{O}_{5}+x \mathrm{Li}_{2} \mathrm{O}$ glasses", J. Non-Cryst. Solids 354, pp. 3152-3158, 2008.

38. Y. Wang, S. Dai, F. Chen, T. Xu and Q. Nie, "Physical properties and optical band gap of new tellurite glasses within the $\mathrm{TeO}_{2}-\mathrm{Nb}_{2} \mathrm{O}_{5}-\mathrm{Bi}_{2} \mathrm{O}_{3}$ system", Mater. Chem. Phys., vol. 113, pp. 407-411, 2009.

39. V. Dimitrov and S. Sakka, "Linear and nonlinear optical properties of simple oxides. II", J. Appl. Phys., vol. 79, pp. 1741-1745, 1996.

40. D.C. Ghosh and R. Biswas, "Theoretical Calculation of Absolute Radii of Atoms and Ions. Part 2. The Ionic Radii", Int. J. Mol. Sci., vol. 4, pp. 379-407, 2003.

41. H. Ticha, J. Schwarz, L. Tichy and R. Mertens, "Physical Properties of PbO-ZnO- $\mathrm{P}_{2} \mathrm{O}_{5}$ Glasses II. Refractive Index and Optical Properties", J. Optoelectron. Adv. Mater., vol. 6, pp. 747-753, 2004.

42. V. Dimitrov and T. Komatsu, "Classification of Simple Oxides: A Polarizability Approach", J. Solid State Chem., vol. 163, pp. 100-112, 2002.

43. A. Klinokowski, "Non-Monotonic Variations of Some Parameters in Vitreous $\mathrm{R}_{2} \mathrm{O}-\mathrm{SiO}_{2}$ and $\mathrm{R}_{2} \mathrm{O}-\mathrm{Al}_{2} \mathrm{O}_{3}$ $\mathrm{SiO}_{2}$ Systems", J. Non-Cryst. Solids, vol. 72, pp. 117-137, 1985. 